Louisiana State University

LSU Digital Commons

1967

\title{
The Role of the Red Nucleus in Visually Guided Behavior in the Rat.
}

James Johnston Mcnew

Louisiana State University and Agricultural \& Mechanical College

Follow this and additional works at: https://digitalcommons.Isu.edu/gradschool_disstheses

\section{Recommended Citation}

Mcnew, James Johnston, "The Role of the Red Nucleus in Visually Guided Behavior in the Rat." (1967). LSU Historical Dissertations and Theses. 1306.

https://digitalcommons.Isu.edu/gradschool_disstheses/1306

This Dissertation is brought to you for free and open access by the Graduate School at LSU Digital Commons. It has been accepted for inclusion in LSU Historical Dissertations and Theses by an authorized administrator of LSU Digital Commons. For more information, please contact gradetd@lsu.edu. 
This dissertation has been

microflimed exactly as recolved $\quad 67-14,001$

McNEW, James Johnston, 1936-

THE ROLE OF THE RED NUCLEUS IN VISUALLY GUIDED BEHAVIOR IN THE RAT.

Louisiana State University and Agricultural and Mechanical College, Ph.D., 1967

Psychology, experimental

University Microfilms, Inc., Ann Arbor, Michigan 
THE ROLE OF THE RED NUCLEUS IN VISUALLY GUIDED BEHAVIOR IN THE RAT

\section{A Dissertation}

Submitted to the Graduate Faculty of the Louisiana state University and Agricultural and Mechanical College in partial fulfillment of the requirements for the degree of Doctor of Philosophy in The Department of Psychology by James Johnston McNew B.A., Ohio Wesleyan University, 1958 M.A., Louisiana State University, 1965 May, 1967 


\section{ACKNOWLEDGMENT}

The author wishes to express $\mathrm{his}$ appreciation and gratitude to others involved in his research project. Special thanks go to Dr. Robert Thompson, chairman of his committee, and to Barbara R. McNew. Others to whom a debt is owed are the members of his committee, Dr. Donald R. Hoffeld, Dr. A. Clinton Pereboom, Dr. Billy M. Seay, Dr. John R. Stabler, and Dr. Nick B. Poponjac. The author would also like to express his gratitude to his colleagues at the Brain Research Laboratory and particularly to Mrs. Vera M. Foil for preparation of the final draft.

The research was aided by Grant MH-08377-03 from the National Institute of Mental Health, United States Public Health Service. 
TABLE OF CONTENTS

PAGE

TITLE PAGE . . . . . . . . . . . . . . . . 1

ACKNOWLEDGMENT . . . . . . . . . . . . . . $1 i$

LIST OF TABLES . . . . . . . . . . . . . . . iv

LIST OF FIGURES . . . . . . . . . . . . . . . . v v

ABSTRACT . . . . . . . . . . . . . . . vi

INTRODUCTION . . . . . . . . . . . . . . 1

The Problem ................. . . . 9

METHOD . . . . . . . . . . . . . . . . 11

Subjects . . . . . . . . . . . . ... 11

Apparatus .................... 11

Procedure .................. 11

Preliminary training ............. . . 11

Discrimination training . . . . . . . . . 12

Postoperative testing .............., 13

Behavioral observations . . . . . . . . . 13

Retention testing ............... 14

Surgery and histology ............ 15

RESULTS . . . . . . . . . . . . . 17

Retention of size discrimination......... 17

Retention of form discrimination......... 21

Size threshold discriminations . . . . . . . . . . 21

Correlations.................. 21

Lesions locus and performance .......... . 24

Other behavioral observations . . . . . . . . . 31

DISCUSSION . . . . . . . . . . . . . 40

SUMMARY ..................... . . . 4 46

REFERENCES . . . . . . . . . . . . . . . . . 48 48

VITA .................... 53 


\section{LIST OF TABLES}

TABLE

PAGE

I. Learning and Retention of the Size Discrimination for the Controls and Three Operate - Groups . . . . . . . . . . . . 18

II. Learning and Retention of the Form Discrimination for the Controls and Three Operate Groups . . . . . . . . . . . . . .

III. Number of $\mathrm{Ss}$ in Each Group Meeting Criterion on the Size Threshold Discrimination Tasks . 20

IV. Spearman Rho Correlations Computed on the Operate $\underline{s}$. . . . . . . . . . . . 22 


\section{LIST OF FIGURES}

FIGURE

PAGE

1. Unstained Sections Showing Bilateral LeBions

in the Region of the Red Nucleus... . . . 25

2. Unstained Sections Showing Bilateral Lesions

in the Anterior Region of the Red Nucleus. - 27

3. Unstained Sections Showing Bilateral Lesions

Dorsal to the Region of the Red Nucleus . . 29

4. Unstained Sections Showing a Bilateral Lesion

Centered between the Central Grey and Red

Nucleus ........... . . 30

5. Unstained Sections Showing Asymmetrical

Lesions in the Midbrain . . . . . . . 32

6. Unstained Sections Showing Bilateral Lesions in the Red Nucleus............

7. Unstained Sections Showing Bilateral Lesions Dorsal to the Red Nucleus . . . . . . . 34

8. Unstained Sections Showing Asymmetrical Lesions in the Midbrain . . . . . . . . .

9. Unstained Sections Showing Asymmetrical Lesions of the Midbrain . . . . . . . . . 


\section{ABSTRACT}

The purpose of the present study was to ascertain whether the abolishment of visual discrimination habits by damage to the area of the red nucleus results primarily from a sensory-perceptual loss or an integrative-memory deficit. Normal and midbrain damaged rats were first tested for retention of a preoperatively learned visual size discrimination, then tested on size discrimination threshold, and subsequently tested for retention of a visual form discrimination habit. Bilateral red nucleus lesioned ss did significantly poorer on retention tasks than controls and $\underline{S}$ receiving more dorsal or asymmetrical miabrain lesions. Red nucleus $\underline{S} s$ performed poorer than controls, but not other midbrain $\underline{S} s$, on visual threshold tasks. The results were interpreted within a centrencephalic view of brain functioning. 


\section{INTRODUCTION}

There 1s considerable evidence that the region of the red nucleus plays an important role in mediating learned responses in the rat. For example, it has been found that bilateral damage to this ventral midbrain area impairs retention of an avoidance response to photic and auditory stimuli (Thompson, Rich, \& Langer, 1964), abolishes a previously learned kinesthetic habit (Thompson, Lukaszewska, Schweigerdt, \& McNew, 1967), and seriously interferes with the retention of brightness (Thompson, et al., 1964) and form discrimination habits (Thompson, et al., 1967). Similar findings have been obtained in cats with rubral damage (Myers, 1964; Sprague, et al., 1963). The proposed research is chiefly concerned with the nature of this retention deficit produced by lesions in the vicinity of the red nucleus. In interpreting the nature of the impairment, the following possibilities will be considered: (1) a peripheral motor disturbance, (2) an attentional deficit, (3) an impairment in emotional-motivational functioning, (4) a sensory-perceptual deficit, and (5) an interference with integrative and memory functioning.

(1) Peripheral motor disturbance. The red nucleus is an extrapyramidal motor structure receiving afferents from the motor cortex (Rinvik, 1965; Knook, 1966), the globus 
pallidus, the dentate nucleus via the brachium conjunctivium (Hassler, 1950; June \& Hassler, 1960), and the surrounding extrapyramidal motor nuclei of the midbrain, such as the substantia niqra and the reticular formation (Carpenter \& McMasters, 1964). The major descending efferent extrapyramidal projections are to the spinal cord by the way of the rubrospinal tract and to the lower olives and reticular formation through the central tegmental tract. The former efferent projection is more prominent in the rat (Jung \&assler, 1960).

Several lines of evidence suggest that poor retention performance following rubral damage is not attributable to a peripheral motor disturbance. First, Thompson, et al. (1964) noted in their visual discrimination and avoidance conditioning experiments that rats with rubral damage manifested no observable motor deficits after a two week recovery period. Secondly, Thompson and Massopust (1960) showed that a peripheral motor disturbance is not necessarily correlated with inferior retention performance. They found that although a number of animals with brain stem damage displayed marked motor deficits, many of these $\underline{S}$ s achieved perfect retention scores of a visual discrimination habit. They also reported that one rat which sustained damage to the cerebellar nuclei (dentate, emboliform, fastigial, and restiform nuclei) and consequently manifested a severe motor deficit, succeeded in performing perfectly during the retention test. Finally, it 
has been reported in the literature that bilateral destruction of extrapyramidal structures located more rostrally in the brain, such as the frontal cortex (Lashley, 1929;

Thompson, 1960), caudate nucleus and globus pallidus (Thompson \& Massopust, 1960) has no significant effect on retention of a visual habit.

(2) Attentional deficit. That an attentional deficit might be responsible for the poor retention performance is suggested by the fact that rubral damage involves destruction, in part, to the ascending midbrain reticular substance. Indeed, it is not uncommon in the literature for the red nucleus to be referred to as a specialized derivative of the reticular formation (Allen, 1932; French, 1960), as a portion of the nucleus tegmenti motorius (Brodal, 1948), or as the so-called substantis reticularis mesencephali (Carpenter, 1956). In any respect, rubral lesions reported by Thompson and his collaborators (personal communication) involved damage to the surrounding reticular formation as well as damage to the medial leminiscus and ventral tegmental area of Tsai.

According to Magoun (1958, p. 64), "ascending reticular influences . . are importantly, and probably essentially, concerned with initiating, maintaining, and modifying such states as wakefulness, attention, or arousal." Although not opposed to the view that the midbrain reticular formation is 
of importance to these states of wakefulness, attention, or arousal, there is considerable evidence that an attention deficit due to reticular damage is not the primary cause of the retention losses cited above. For example, bilateral lesions of the midbrain reticular formation situated laterally and dorsally to the red nucleus produce no retention deficit of a visual discrimination habit (Thompson, 1963a; Thompson, et al., 1964). This has also been found to be true for large lesions of the midline and reticular nuclei of the thalamus (Thompson, 1963a). In an avoidance response to a visual stimulus, rats with rubral damage, despite the severe retention impairment, displayed anticipatory fear responses forientation toward the top of the box to which $\underline{S}$ must jump to avoid shock, abrupt cessation of breathing, and squeaking) to the onset of a visual signal (Thompson, et al., 1964). Of further interest is that Ss suffering damage to the more lateral and dorsal aspects of the midbrain reticular formation manifested no deficit in retention of the avoidance habit (Thompson, 1963b; Thompson, et al., 1964).

Additional evidence is given by sprague, et al. (1963), who reported that cats with medial midbrain reticular lesions display good attention and orientation when stimulated. And, in a recent study by Ellen, Wilson, and Powell (1965), ss with rubral damage were able to learn and maintain a bar pressing response under fixed interval reinforcement, achieving response records very similar to normals. With the 
assumption that the discriminative dimension of fixed interval behavior reflects temporal discrimination, they concluded that it is unlikely that rubsal lesions produced any significant alterations in attention. Although it may be naive to assume that an attentional factor is not involved in the loss of visual discrimination habits following rubral damage, there seems to be suggestive evidence that it is not primarily responsible for the impairment.

(3) Emotional-motivational disturbance. Sprague, et al. (1963) have reported that large bilateral lesions destroying almost all of the medial structures of the midbrain (including the red nucleus) have disasterous effects on the learning of a black-white discrimination, a bidirectional conditioned avoidance response, and a conditioned leg flexion response. These large medial midbrain lesions rendered the animal generally drowsy and hypoactive, but this state could be changed to a very attentive, highly distractible, and hyperemotional one by the administration of sudden stimuli. According to these authors, when shock is

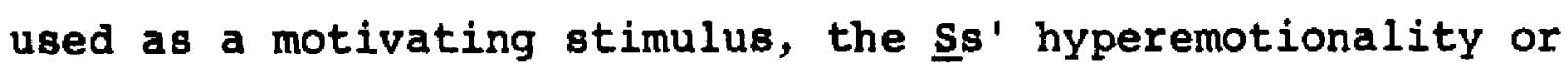
irritability to nocioceptive stimuli is considered to be responsible for the animals' poor acquisition performance. However, it must be pointed out that hyperemotionality to nocioceptive stimuli in itself is not necessarily related to poor retention performance. This conclusion is based upon 
the finding that $\underline{S}$ suffering damage to such structures as the septal area or medial hypothalamus show good retention of a visual discrimination habit with avoidance (escape) from shock as a motive (Thompson \& Massopust, 1960; Thompson, 1963a). During postoperative training, these limbic lesioned So displayed ferocity to handing.

(4) Sensory-perceptual deficit. The foregoing review indicates that neither a peripheral motor disturbance, an attention deficit, nor hyperemotionality is sufficient to explain the observed impairment in retention produced by rubral lesions. Because this ventral midbrain area is fat. removed from the classical ascending sensory pathways to the cortex, a sensory-perceptual deficit as a possible explanation of the retention loss may seem highly unlikely. However, it is well known that either intracranial stimulation or lesions of brain structures outside of the visual pathways do influence visual acuity and perceptual organization. For instance, Fuster (1958) has demonstrated that stimulation of the reticular formation lowers visual thresholds in monkeys. Furthermore, perception of hidden figures by humans is strongly influenced by lesions localized anywhere in the cerebral cortex (Teuber, 1960). According to centrencephalic theory (Penfield, 1954; Thompson, 1965), perception of a visual stimulus is not achieved until optic impulses are relayed from the visual cortical centers to the 
higher brain stem. Destruction of the red nucleus may interrupt these corticofugal projections, thus producing a sensoryperceptual deficit.

Anatomically, the region of the red nucleus receives both direct and indirect descending fibers from the occipital cortical areas (Knook, 1966). By the way of the pretectal area, afferents reach this midbrain region also from the parietal and temporal cortical areas (Knook, 1966; Gerebtshoff \& Wauters, 1941; 1943).

Although behavioral evidence seems to indicate that rubral damaged rats have the sensory equipment to respond to the onset of light (Thompson, et al., 1964), this does not necessarily infer that a sensory deficit is not involved in the performance of visual brightness or form discriminations. For example, interruption of occipitofugal projections by damage to the nucleus posterior thalami results in loss of a thirst motivated visual discrimination habit (McNew, B. \& Thompson, 1966) but has no effect on a thirst motivated approach response to the onset of light (Breen \& Thompson, 1966). Thus, a sensory deficit cannot be entirely ruled out as a possible explanation of the impairment found in visual discrimination habits following rubral damage.

(5) Interference with integrative and memory functioning. Anatomically, the posterior lateral hypothalamus and ventral mesencephalon are interrelated (Crosby \& 
Woodburn, 1951; Krleg, 1932; Nauta, 1958). This hypothalamomesencephalic area (HMA) most likely contains the circuits necessary for the integration and execution of locomotor behavior (Kinsey, Ranson, \& McNatin, 1930; Keller, 1932; Waller, 1940), sequential behavior (Delgado, 1964), the defense reaction (Bard, 1928; Abrahams, Hilton, \& Zbrozyna, 1960), and other somatic behavior patterns (Wood, 1964). Damage to either the posterior lateral hypothalamus or the ventral mesencephalon (substantia nigra and red nucleus) produces devastating effects on previously acquired visual, and auditory, and kinesthetic habits (Thompson, 1965; 1963a; 1963b; Thompson, et al., 1964; Thompson, Malin, \& Hawkins, 1961; Thompson, et al., 1967).

One interpretation of these data is that the HMA serves as the integrative link between the sensory, motivation, and motor system, where "memory traces" are formed. This view, related to Penfield's centrencephalic theory, has been elaborated in previous papers (Thompson, 1965; 1963b; Rich \& Thompson, 1965; Thompson, et al., 1964). With respect to visual discrimination performance, this theory states that the habit is elicited and maintained by activity of a descending occipito-pretecto-tegmental pathway terminating in the region of the red nucleus, substantia nigra, and the nucleus cuneiformis. Interestingly, this latter structure also receives a direct occipito-tegmental projection which 
may be of additional importance in form discrimination habits. The memory trace is hypothesized to develop within the fMA at. the terminal endings of these descending fiber tracts. Functionally, damage to the occipital cortex, pretectal area, nucleus cunelformis, posterior lateral hypothalamus, or the region of the red nucleus and substantia nigra have all been found to consistently yield positive effects; that is, a significant retention deficit of visual discrimination habits (Thompson \& Massopust, 1960; Thompson, 1960; 1963a; 1965; Thompson \& Rich, 1963; Thompson, et al., 1964; McNew, B. \& Thompson, 1966; Thompson, et al., 1967).

\section{THE PROBLEM}

The present study attempted to investigate further the retention loss of visually guided behavior following HMA damage. More specifically, the study was designed to ascertain whether the abolishment of the visual discrimination habit by damage to the region of the red nucleus results primarily from a sensory-perceptual deficit or an integrativememory deficit, as is suggested by Thompson's proposed centrencephalic theory (Thompson, 1965). Rats were initially trained on a visual size discrimination (large circle vs. small circle) and then on a form discrimination problem (horizontal vs. vertical stripes), after which they received bilateral fed nucleus damage. Following an ample recovery 
period, normal and operated $\underline{S} s$ were tested for retention of the size discrimination. Upon relearning this problem, the Ss were tested on size discrimination threshold and subsequently tested for retention of the form discrimination habit. Under the assumption that a memory deficit rather than a pure sensory-perceptual loss is involved, $\underline{S} s$ suffering red nucleus damage were expected to manifest retention losses on both size and form discrimination habits, but perform favorably on the size threshold discrimination task. 


\section{METHOD}

\section{Subjects}

Thirty-one adult male albino rats of the wistar strain were ueed. Following discrimination learning, 22 of these Ss were subjected to bilateral lesions of the midbrain tegmentum. The remaining 9 Ss served as normal controls.

\section{Apparatus}

The apparatus was a two-choice discrimination box similar to that described by Thompson and Bryant (1955). It consisted of a start box, choice chamber, and goal box. The former two compartments contained a grid floor, while the floor of the goal box was made of wood. The only means pro$v i d e d$ for $\underline{S}$ to enter the goal box was by pushing aside one of two stimulus cards which were placed behind the two 5-inch square windows located at the end of the choice chamber. The grid section located in front of each window was wired independently from the remaining grid floor. All parts of the grid were connected to a variable powerstat.

\section{Procedure}

Preliminary training. On Day 1 , each $\underline{\mathrm{s}}$ was allowed to explore the goal box of the apparatus for 15 minutes. On Day 2, each $\underline{s}$ was trained to enter the goal box in order 
to avoid (escape) shock by pushing aside grey stimulus cards situated at the windows. This was accomplished in the following manner: $\underline{s}$ was placed in the start box and the door raised. Failure to leave the start box within 5 seconds was followed by a brief shock. If the $\underline{s}$ did not enter the goal box within 30 seconds, additional shocks were given. On the first trial, the stimulus cards were placed at a 45 degree angle with the window. With repeated trials, the stimulus cards were gradually situated at a smaller angle until they were flush against the window. Preliminary training was terminated when $\underline{S}$ ran from the start box into the goal box, pushing aside the fiush stimulus card, for 3 successive trials.

Discrimination training. All ss were first trained on a size discrimination problem and subsequently trained on a form discrimination problem. On the size discrimination problem, $\underline{\mathbf{S}}$ was trained to respond positively to a black stimulus card with a white circle 4 inches in diameter, and negatively to a black stimulus card having a white circle $1-3 / 4$ inches in diameter. A response to the positive stimulus card admitted $\underline{s}$ to the goal box, whereas a response to the locked negative stimulus card was automatically followed by a shock to the feet. The positive stimulus was varied from the right to the left window in a double alternation order. S received 8 trials daily, with an intertrial 
interval of 60 seconds. The specific training procedure was as follows: $\mathbf{S}$ was placed in the start box and the door raised. If $\underline{S}$ failed to leave the start box within 5 seconds, the grid floor was briefly charged. No further shock was given unless $\underline{\mathbf{S}}$ committed an error or unless a choice was not made within 30 seconds. An error was defined as an approach response to the negative card which brought $\underline{s}^{\prime} s$ forefeet in contact with the charged grid section. Training on the size discrimination problem was terminated when $\underline{S}$ had reached the criterion of 15 correct responses within 2 consecutive days. Form discrimination learning was instituted on the day following mastery of the size discrimination. The procedure for the two problems was identical; only the stimuli to be discriminated differed. On the form discrimination problem, $\underline{\mathbf{s}}$ was trained to respond positively to a black and white horizontally striped card and negatively to an adjacent black and white vertically striped card. The striations were $1 / 2$ inch in width.

From 24 to 48 hours after the learning of the second discrimination problem, 22 Ss were subjected to bilateral midbrain damage, while the remaining 9 constituted the normal controls.

Postoperative testing

Behavioral observations. On the day following surgery and each day thereafter until the institution of 
retention testing, records were kept on each $\underline{\mathbf{s}}$ as to weight, ease in handling, posture, and locomotor behavior. The number of days for $\underline{S}$ to regain preoperative weight served as the measure in ranking recovery difficulty. In case of ties, the proportion of weight $108 s$ was considered.

Retention testing. Following a recovery period of 21 to 26 days, the operated and 4 of the 9 normal animals were required to relearn the size discrimination. The 5 remaining controls were given an additional 60 to 90 days between acquisition training and the initiation of retention testing. This lengthened rest interval for the 5 normals was introduced to approximate the time interval that the operates received between acquisition and the retention testing on the form discrimination.

In the relearning of the size discrimination, percentage of error savings constituted the measure of retention. The procedure was the same as in the original learning unless $\underline{S}$ failed to relearn the size discrimination with $0 \%$ savings. At $0 \%$ savings, the procedure was modified for the purpose of facilitating relearning. A black stimulus card and subsequently a stimulus card with a circle $7 / 8$ inches in diameter were substituted for the original negative stimulus card. Upon acquisition of these simpler discriminations, the original procedure was again instituted. with the modification in procedure, percentage of daily 
session savings (in conjunction with the $0 \%$ error savings) to relearn the original size discrimination served in ranking $\underline{S} s$ on retention performance.

Subsequent to the relearning of the size discrimination problem, $\underline{S} s$ were tested on discriminations of greater difficulty along the size dimension. S s were successively required to learn (not making more than one error within a daily session of 8 trials) size discriminations in order of difficulty, where the positive stimulus card with a 4 inch circle was paired with negative stimulus cards having circles of $1-3 / 4$ inches, 2 inches, $2-1 / 2$ inches, and 3 inches in diameter.

After learning the four size threshold discriminations, or if $\underline{S}$ failed to learn any threshold problem within 15 errors, size threshold testing was terminated. In the latter case, $\underline{s}$ received review training on the original size discrimination until he again met criterion of not making more than 1 error in a daily session.

on the day following size threshold discrimination testing, testing of retention on the form discrimination was instituted. The procedure was the same as in original learning. Percentage of error savings constituted the measure of retention.

Surgery and histology. Operations were carried out under chloral hydrate anesthesia and semiaspectic conditions. 
Bilateral lesions in the region of the red nucleus were produced by electrocoagulation (constant current of 2 ma passing for 10 seconds through an electrode with $1.0 \mathrm{~mm}$ exposed). The lesions were accomplished with a Baltimore stereotaxic instrument. The coordinates used on the majority of operated Ss corresponded to frontal $.25 \mathrm{~mm}$, lateral $1.0 \mathrm{~mm}$, and ventral $6.5 \mathrm{~mm}$ on the rat atlas of Massopust (1961). Following postoperative testing, each operated $\underline{s}$ was sacrificed with an overdose of Nembutal. The brain was then removed, fixed in $10 \%$ formalin for 48 hours, and then sectioned frontally at $60 \mu$ with a freezing microtome. Every third section through the lesioned area was photographed at $10 \mathrm{X}$ with the use of: a Leitz enlarger.

Estimates of the size of damage to the lesioned area were determined in a manner similar to that described by $B$. McNew (1965). The photograph of the brain section showing the greatest amount of necrotic damage for each $\underline{s}$ was selected. The central necrotic damage was delineated on tracing paper. Then, to estimate the relative size of the lesion, a transparent grid divided into $1 / 16$ inch squares was superimposed over the trased lesion and the squares counted. 


\section{RESULTS}

Histologies showed that 8 Ss suffered midbrain damage to the area dorsal to the medial lemniscus wherein lies the red nucleus (group RN). Seven Ss received lesions of the midbrain dorsal to the red nucleus (group DRN) and 7 ss were found to have bilaterally asymmetrical midbrain lesions (group AML). Non-parametric analyses of variance (Kruskal \& Wallis, 1952) computed on the above three groups and the normal controls (group NC) with respect to (1) retention of size discrimination, (2) retention of form discrimination, and (3) size threshold discrimination were found to yield significant H's of (1) 23.65 (p<.001), (2) $16.66(\mathrm{p}<.001)$; and (3) $11.15(p<.02)$, respectively. Tables I, II, and III summarize the subsequent U tests carried out among the 4 groups (Mann \& Whitney, 1947).

Retention of size discrimination

On the retention of the size discrimination task, group RN was found to perform significantly poorer than groups NC, DRN, and AML. Group AML performed significantly poorer than both group NC and group DRN. Group DRN showed significantly poorer retention than group NC only. 
TABLE I

LEARNING AND RETENTION OF THE SIZE DISCRIMINATION FOR THE CONTROLS AND THREE OPERATE GROUPS

\begin{tabular}{|c|c|c|c|c|c|c|}
\hline Group & $\mathrm{N}^{ \pm}$ & $\frac{\text { arning }}{\text { Mean }}$ & $\frac{\text { Size Discrim. }}{\text { Range }}$ & $\begin{array}{l}\frac{\text { Retenti }}{\text { Mean \% }} \\
\text { Savings }\end{array}$ & $\frac{\text { Lon of Size Di }}{\text { Range }}$ & $\frac{\text { scrim. }}{\text { Sign. }}$ \\
\hline NC & 9 & 44.8 & $26-58$ & $83.6 \%$ & $100 \%-65 \%$ & \\
\hline RN & 8 & 41.0 & $26-57$ & $-390.3 \%$ & $-145 \%-(-708 \%)$ & $A, B, C$ \\
\hline DRN & 7 & 41.0 & $28-66$ & $-47.8 \%$ & $89 \%-(-207 \%)$ & $\mathbf{a}$ \\
\hline AML & 7 & 48.3 & $29-63$ & $-185.0 \%$ & $-27 \%-(-347 \%)$ & $A, b$ \\
\hline
\end{tabular}

A Retention deficit significantly greater than that of NC at the .01 level.

${ }^{a}$ Retention deficit significantly greater than that of NC at the .05 level.

Betention deficit significantly greater than that of DRN at the .01 level.

$b_{\text {Retention deficit significantly greater than that of }}$ DRN at the .05 level.

Retention deficit significantly greater than that of AML at the .05 level. 
TABLE II

LEARNING AND RETENTION OF THE FORM DISCRIMINATION FOR THE CONTROLS AND THREE OPERATE GROUPS

\begin{tabular}{|c|c|c|c|c|c|c|}
\hline \multirow{2}{*}{$\begin{array}{l}\text { Group } \\
\text { NC }\end{array}$} & \multicolumn{2}{|c|}{ 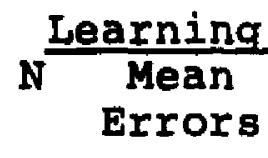 } & \multirow{2}{*}{$\frac{\frac{\text { Form Discrim. }}{\text { Range }}}{7-49}$} & \multicolumn{3}{|c|}{$\begin{array}{l}\text { Retention of Form } \text { Discrim. } \\
\text { Mean \% } \\
\text { Savings }\end{array}$} \\
\hline & 9 & 19.9 & & $92.4 \%$ & $100 \%-71 \%$ & \\
\hline $\mathbf{R N}$ & 8 & 22.0 & $12-40$ & $-4.6 \%$ & $100 \%-(-100 \%)$ & $A, B, C$ \\
\hline DRN & 7 & 17.1 & $8-35$ & $88.9 \%$ & $100 \%-47 \%$ & \\
\hline AML & 7 & 19.3 & $16-23$ & $41.4 \%$ & $87 \%-(-87 \%)$ & $\mathrm{A}, \mathrm{b}$ \\
\hline
\end{tabular}

${ }^{\text {A }}$ Retention deficit significantly greater than that of NC at the .01 level.

Betention deficit significantly greater than that of DRN at the .01 level.

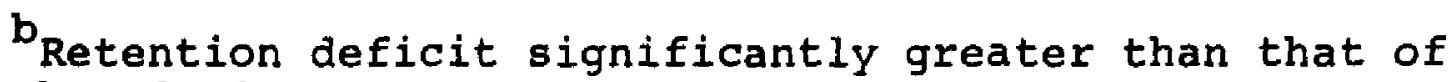
DRN at the .05 level.

Retention deficit significantly greater than that of AML at the .05 level. 
TABLE III

NUMBER OF SS IN EACH GROUP MEETING CRITERION ON THE SIZE THRESHOLD DISCRIMINATION TASKS

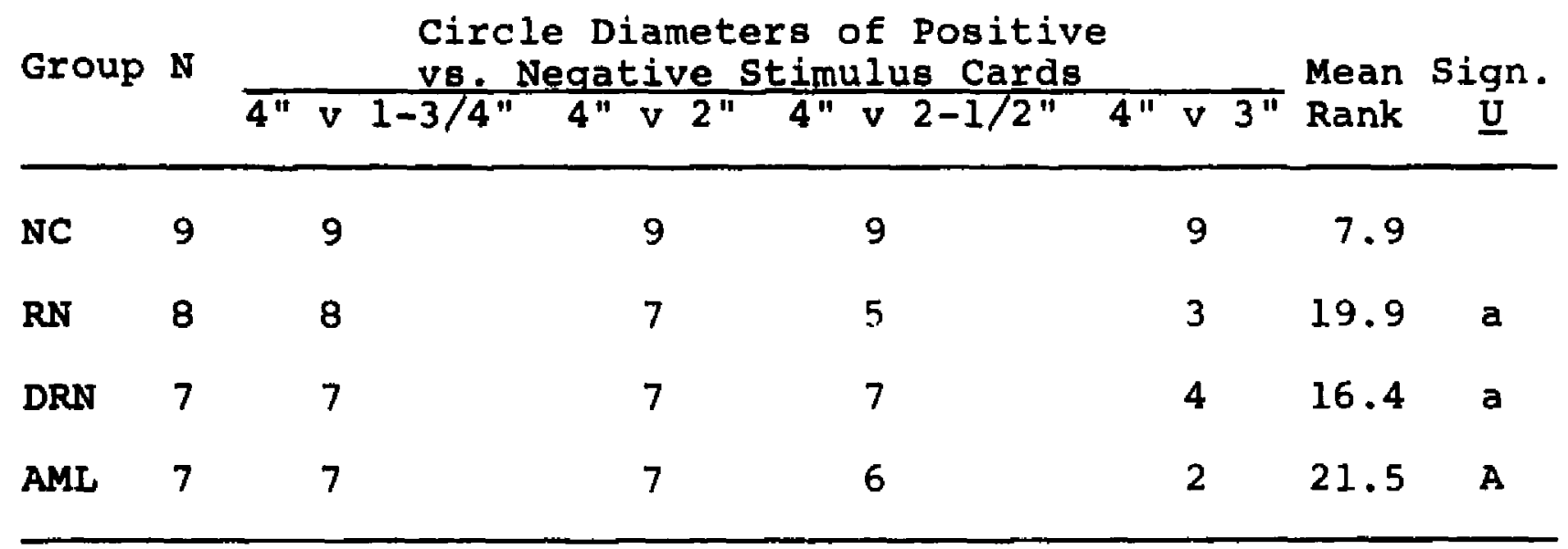

A Threshold deficit significantly greater tinan that of NC at the .01 level.

Threshold deficit significantly greater than that of NC at the .05 level. 
Retention of form discrimination

On retention of the form discrimination, as in the case of the aize discrimination, the group $R N$ was again found to perform significantly poorer than groups DRN, AML, and NC. Group AML showed a significantly greater deficit than either group DRN or group NC. Interestingly, no significant difference in retention of the form discrimination task was found between the groups NC and DRN.

Size threshold discriminations

On the size threshold discrimination tasks (see Table III), the three operate groups were found not to differ significantly from each other. However, each group did perform significantly poorer than the normal controls.

\section{Correlations}

The operates' performance on the size threshold discriminations suggested that a sensory-perceptual loss may be involved in the retention deficits found with midbrain lesions. To investigate this possibility, Spearman Rho correlations (Siegel, 1956) were computed (see Table IV). Retention performance of the operates on the size discrimination tasks and on the form discrimination task was highly correlated $(\underline{r h o}=.73, \mathrm{p}<.01)$. Size threshold discrimination performance was not significantly correlated with retention of the original size discrimination ( $\underline{\text { rho }}=.35$ ), 
TABLE IV

SPEARMAN RHO CORRELATIONS COMPUTED

ON THE OPERATE $\underline{S} s$

Form Discrim. Size Thresh. Lesion Recovery

Retention

Discrim.

Size Diffic.

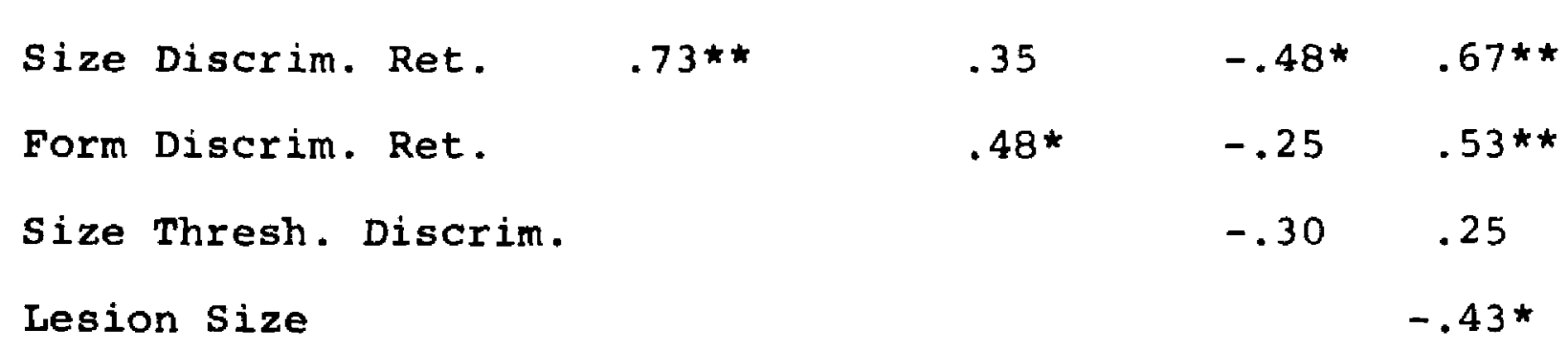

* Rho significant at the .05 level.

** Rho significant at the .01 level. 
but was significantly correlated with retention of the form discrimination task ( $\underline{\underline{y} \text { o }}=.48, p<.05$ ). However, for those $\underline{S} s$ receiving red nucleus damage, size threshold performance was found not to be significantly correlated with retention of the form discrimination task ( $\underline{\text { rho }}=.02)$.

As noted above, the region of the red nucleus seems to be critical for the retention of both the size and form discrimination habits. That lesion size is not responsible for this result is supported by the finding that the magnitude of the midbrain lesion was negatively correlated with postoperative retention as well as threshold performance. This suggested reversal of the mass action effect is clearly attributable to the finding that lesions in the area of the red nucleus were significantly smaller than lesions dorsal to the red nucleus $(\underline{U}=11, p \leq .027)$.

The size of the lesion was also found to be negatively correlated with postoperative recovery ( $\underline{\text { rho }}=-.433$, $\mathrm{p}<.05)$. Again, this negative correlation may be influenced

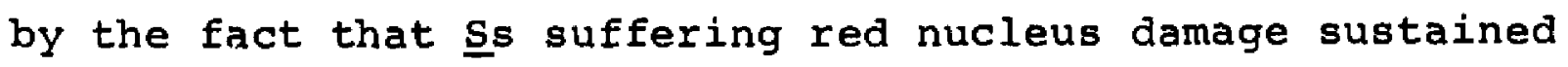
significantly smaller lesions than the group DRN and also that group RN had significantly more difficulty in postoperative recovery than group $D R N(\underline{U}=5, \underline{p}<.003)$. Lesions in the area of the red nucleus not only resulted in greater retention deficits but also caused a greater difficulty in postoperative recovery. Difficulty in recovery was 
significantly correlated with relearning of the size discrimination $(\underline{r h o}=.674, p<.01)$ and form discrimination (rho $=.526, \mathrm{p}<.01$ ). It was not, however, significantly correlated with size threshold discrimination ( $\underline{\text { rho }}=.252$ ) These latter correlations suggest that three rats of the present experiment which failed to recover from ventral midbrain lesions would have shown even more severe disturbances in retention than those manifested by the animals which survived.

Lesion locus and performance

The above analyses strongly implicate the area of the red nucleus as being most critical in the retention of visually guided behavior and also as being of some importance in visual sensory-perceptual processes. Further examination of the lesion locus in relation to S's retention and threshold performance sheds still further light on the importance of the area of the red nucleus.

Figure 1 shows photographs of selected brain sections of $\mathrm{RN}-10$ and RN-34. Both manifested considerable difficulty in relearning the size discrimination task and were unable to relearn the form discrimination within $-100 \%$ savings. The $\underline{s}$, still performing at chance level, were sacrificed at this point. Of special interest is that while these two ss suffered similar lesions and exhibited similar deficits in retention, one $S(\mathrm{RN}-10)$ had very little difficulty, while 


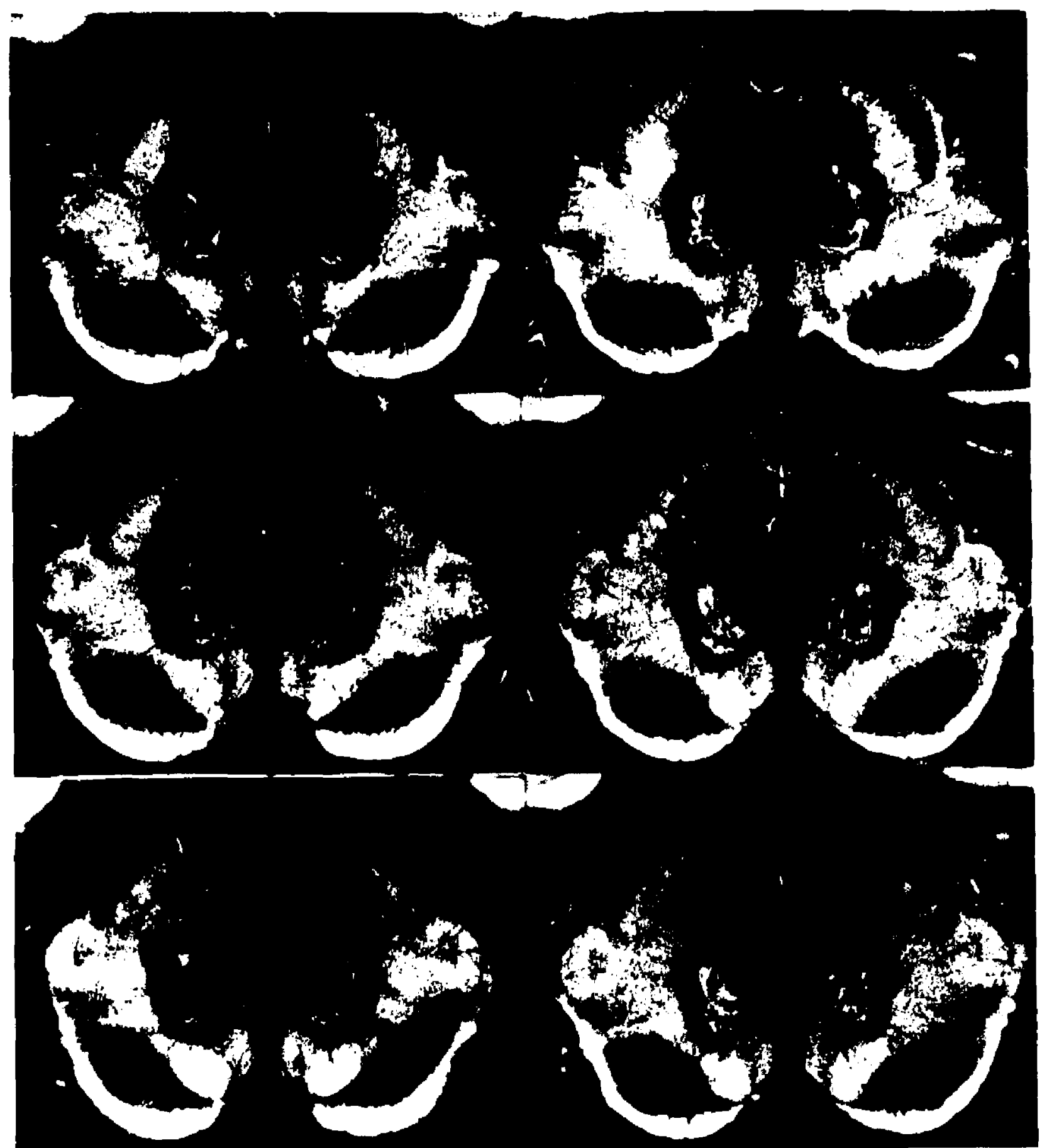

Figure 1. Unstained sections showing bilateral lesions in the region of the red nucleus. Left column: RN-10. Size Retention $=-708 \%$ savings; Threshold errors $=4,0,0,0$; Form Retention $=-100 \%+$. Right column: RN-34. Size Retention $=-560 \%$; Threshold errors $=0,0,15+,-$; Form Retention $=-100 \%+$. 
the other $\underline{S}(R N-34)$ had considerable difficulty with the size threshold discrimination task. RN-10, who met the criterion on the most difficult size discrimination $(4$ inch circle vs. 3 inch circle) without making a single error, did better on the threshold task than 7 of the 9 control 58 . On the other hand, RN-34 failed to learn the intermediate size discrimination ( 4 inch circle vs. $2-1 / 2$ inch circle). Only three other $\underline{S}$ (all operates) failed to meet the criterion on this threshold size discrimination. It is important to note at this point that the same operate $\underline{S}(\mathrm{RN}-10)$, the same attentional, motivational, motoric, sensorial animal who performed perfectly on the most difficult size discrimination, failed to perform better than chance on subsequent retention testing on the form discrimination task.

Figure 2 represents brain sections of two Ss (RN-2 and $\mathrm{RN}-24)$ who received similar lesions of the anterior portion of the red nucleus area. These two rats deserve special consideration because $\mathrm{RN}-24$ represents the one exception found in the group RN. Both $\underline{S} s$ had difficulty in relearning the size discrimination, and both $\underline{S}$ serformed within the normal range on the size threshold discrimination task. However, $\mathrm{RN}-2$ achieved $100 \%$ savings on the form discrimination, whereas $\mathrm{RN}-24$ performed more like his counterparts in group $\mathrm{RN}$, showing only $4 \%$ savings on the form discrimination. This paradoxical finding, along with the 


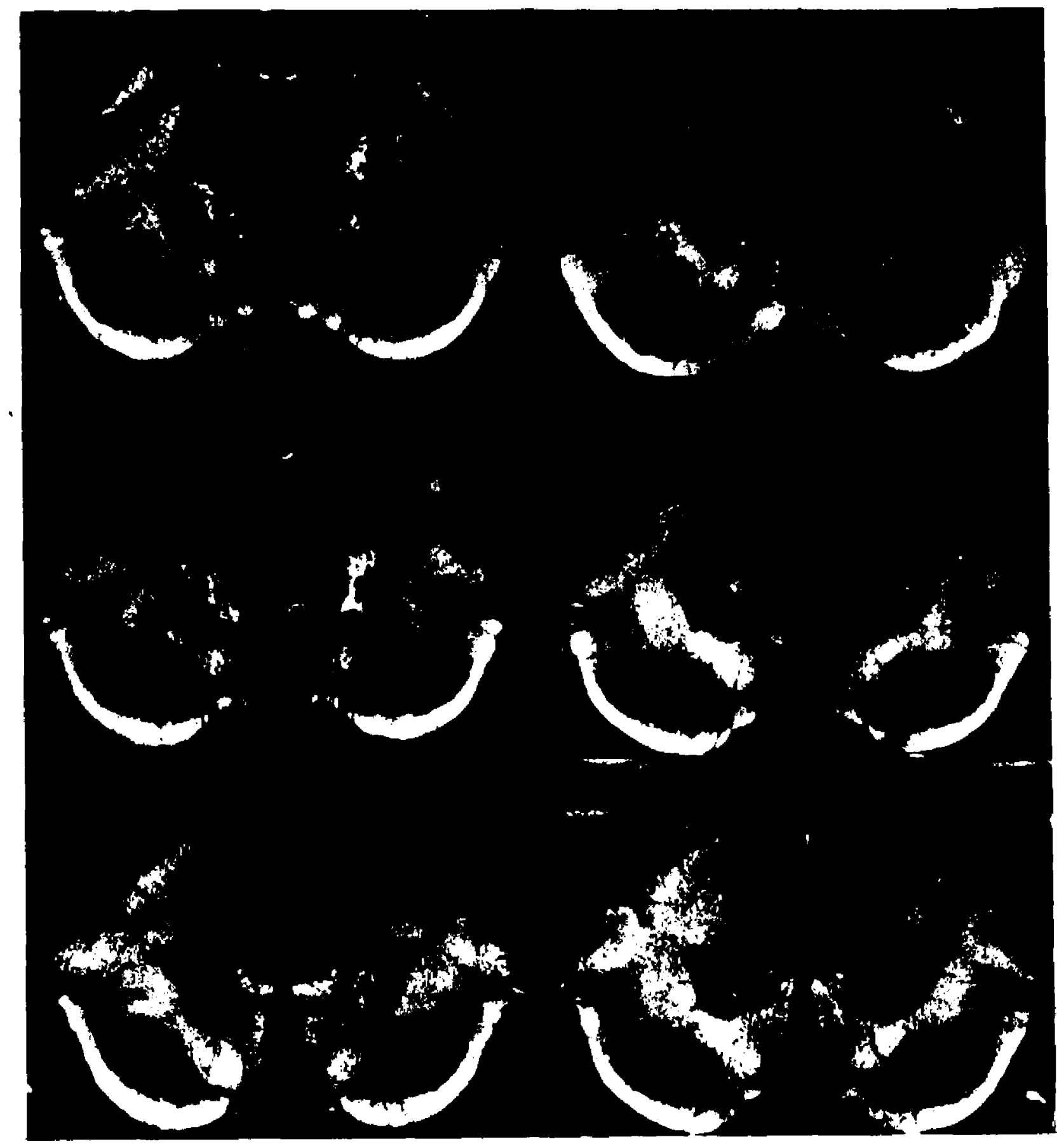

Figure 2. Unstained sections showing bilateral lesions in the anterior region of the red nucleus. Left column: Rarm. Size Retention $=-218 \%$ savings; Threshold errors $=2,4,5,1$; Form Retention $=100 \%$. Right column: RN-24. Size Retention $=-233 \%$; Threshold errors $=2,3,0$, 11 ; Form Retention $=4 \%$. 
observation that the brain damage imposed upon the other 6 $\underline{\text { Ss }}$ in the group $\mathrm{RN}$ was at a level more posterior than the lesions of $\mathrm{RN}-2$ and $\mathrm{RN}-24$, suggests that the anterior region of the red nucleus may not be the most critical area in the maintenance of visual discrimination habits.

In Figures 3 and 4 are presented brain sections of three rats ( $D R N-14, D R N-9$, and $D R N-21$ ) suffering damage dorsal to the area of the red nucleus. In DRN-14, the lesion destroyed a substantial part of the dorsal tegmentum and central grey. DRN-9's lesion was centered within the central grey and DRN-21 received brain damage centered between the central grey and the red nucleus, with the necrotic damage invading only the most dorsal aspect of the red nucleus. These three Ss of group DRN manifested a substantial retention deficit on the first visual discrimination problem (size discrimination), with DRN-21 showing the greater loss. On the size threshold tasks, DRN-14 was unable to meet the criterion on the most difficult discrimination, but performed perfectly on the three easier threshold discriminations. DRN-9 and DRN-21 were both able to meet criterion on the most difficult size discrimination task. On subsequent testing for retention of the form discrimination, DRN-14 achieved an error savings score of $47 \%$, while DRN-9 and DRN-21 showed $100 \%$ savings . 


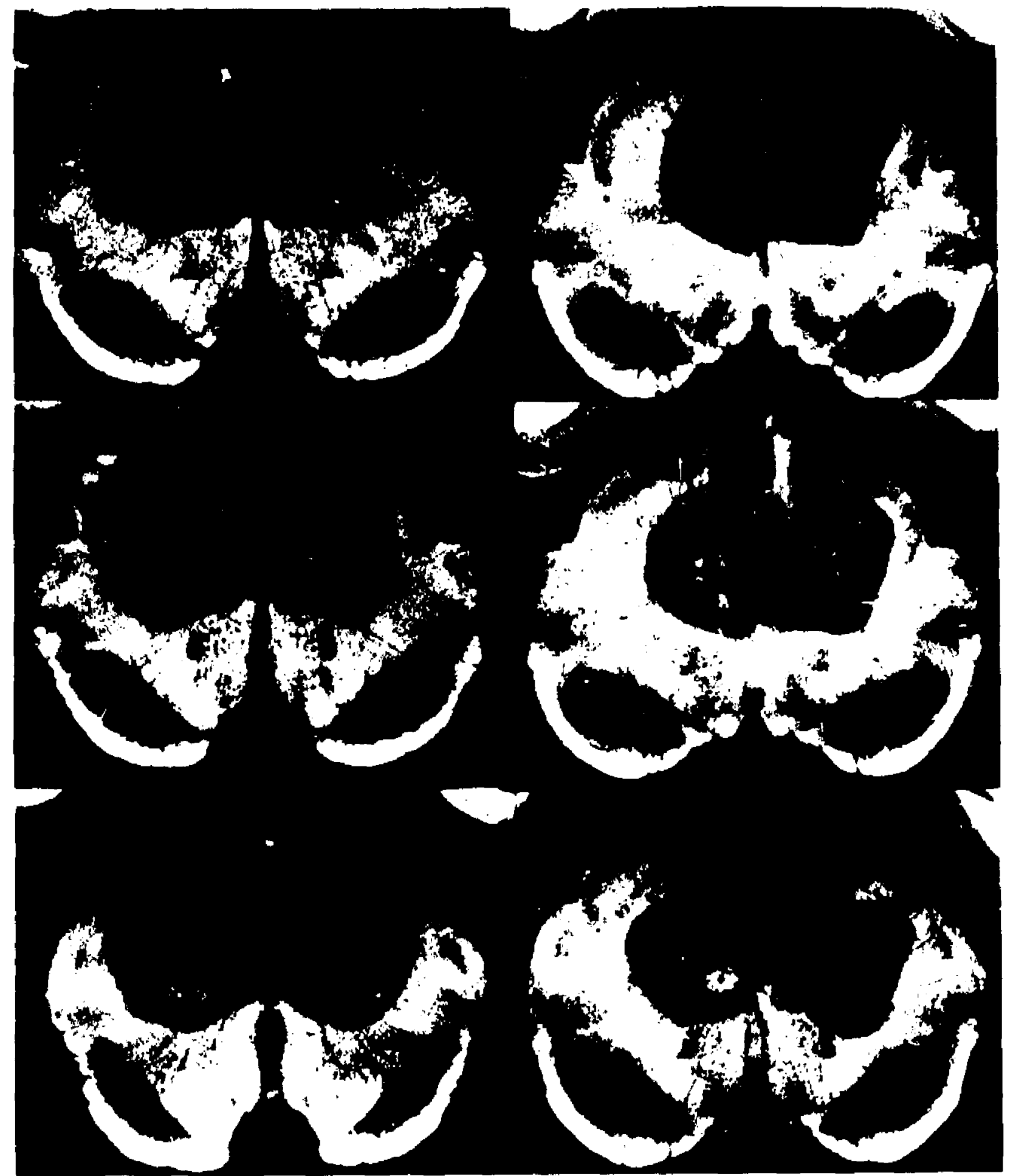

Figure 3. Unstained sections showing bilateral lesions dorsal to the region of the red nucleus. Left column: DRN -14 . Size Retention $=-48 \%$ savings; Threshold errors $=$ $0,0,0,15+$; Form Retention $=47 \%$. Right column: DRN-9. Size Retention $=2 \%$; Threshold exrors $=0,2,6$, 11; Form Retention $=100 \%$. 


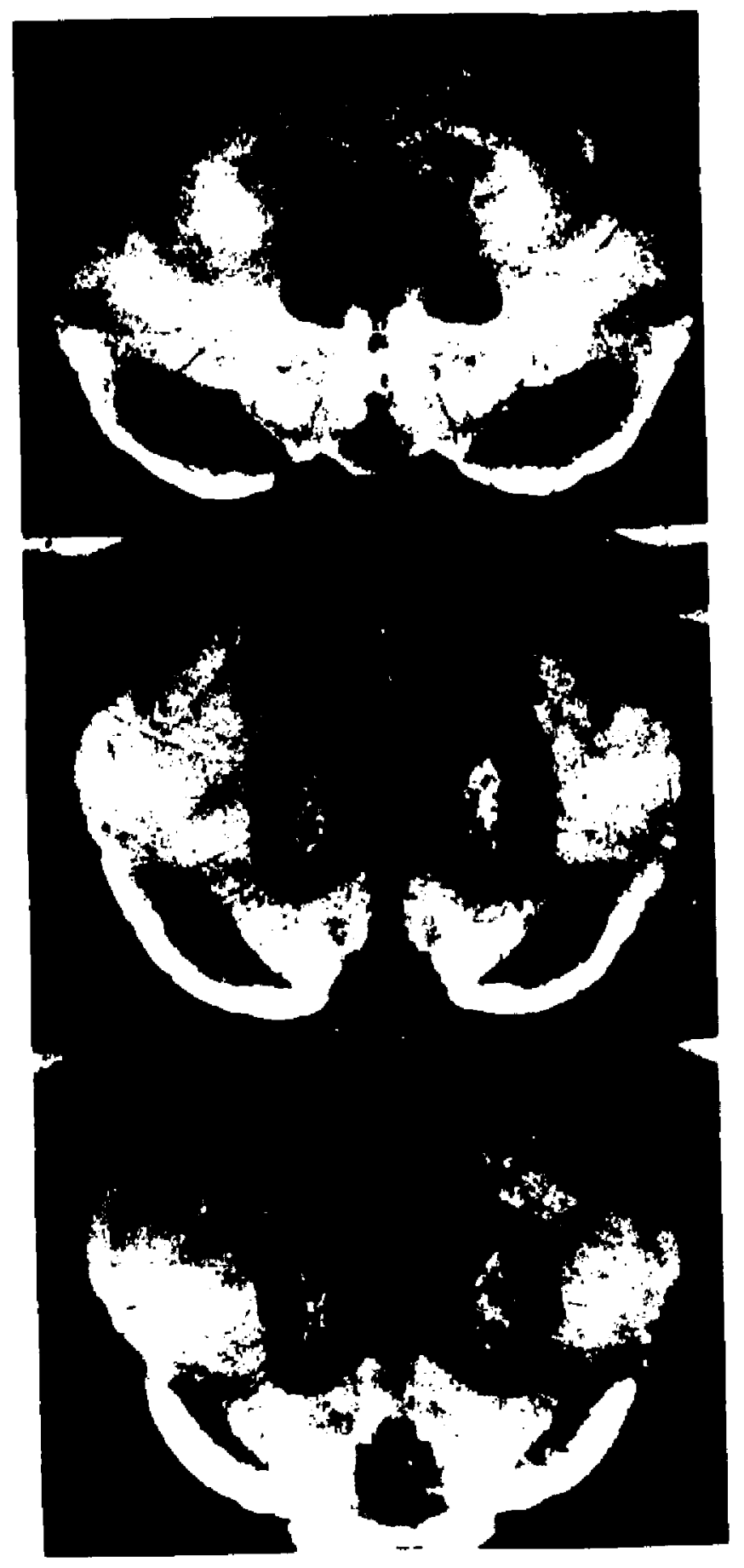

Figure 4. Unstained sections showing a bilateral lesion centered between central grey and red nucleus in DRN-21. Size Retention $=-207 \%$ savings; Threshold errors $=0,0,0,6$; Form Retention $=100 \%$. 
Subjects placed in the asymmetrical group AML all had lesions which invaded at least unilaterally the region of the red nucleus with the exception of AML-25. Figure 5 shows the brain sections of AML-25 and AML-19. AML-25 manifested the best retention and threshold performances of the animals in the group AML, while rat AML-19 manifested the poorest retention and threshold performances of this group.

Information on the remaining 15 operate $\mathbf{s}$ s concerning lesion locus, retention and threshold performance is presented in Figures $6,7,8$, and 9 .

Other behavioral observations

During the course of the postoperative recovery period, several behavioral disturbances were apparent in the experimental animals. These disturbances, which were transitory, included aphagia and adypsia, impaired postural adjustment, absence of pupillo-constrictor response, canting of the head laterally, locomotor circling, obstinate progression, awkwardness of gait, absence of vibrissae movement, paucity of exploratory behavior, and resistance to handling.

Aphagia and adypsia were common behavior disturbances for all three groups. In order to maintain their weight, several forced-feeding techniques were introduced within 72 hours after surgery. The animals were forced to eat a mixture of wet mash, milk, and sugar via (1) forcing food into S's mouth with the use of an eye dropper, spoon, or beaker, 


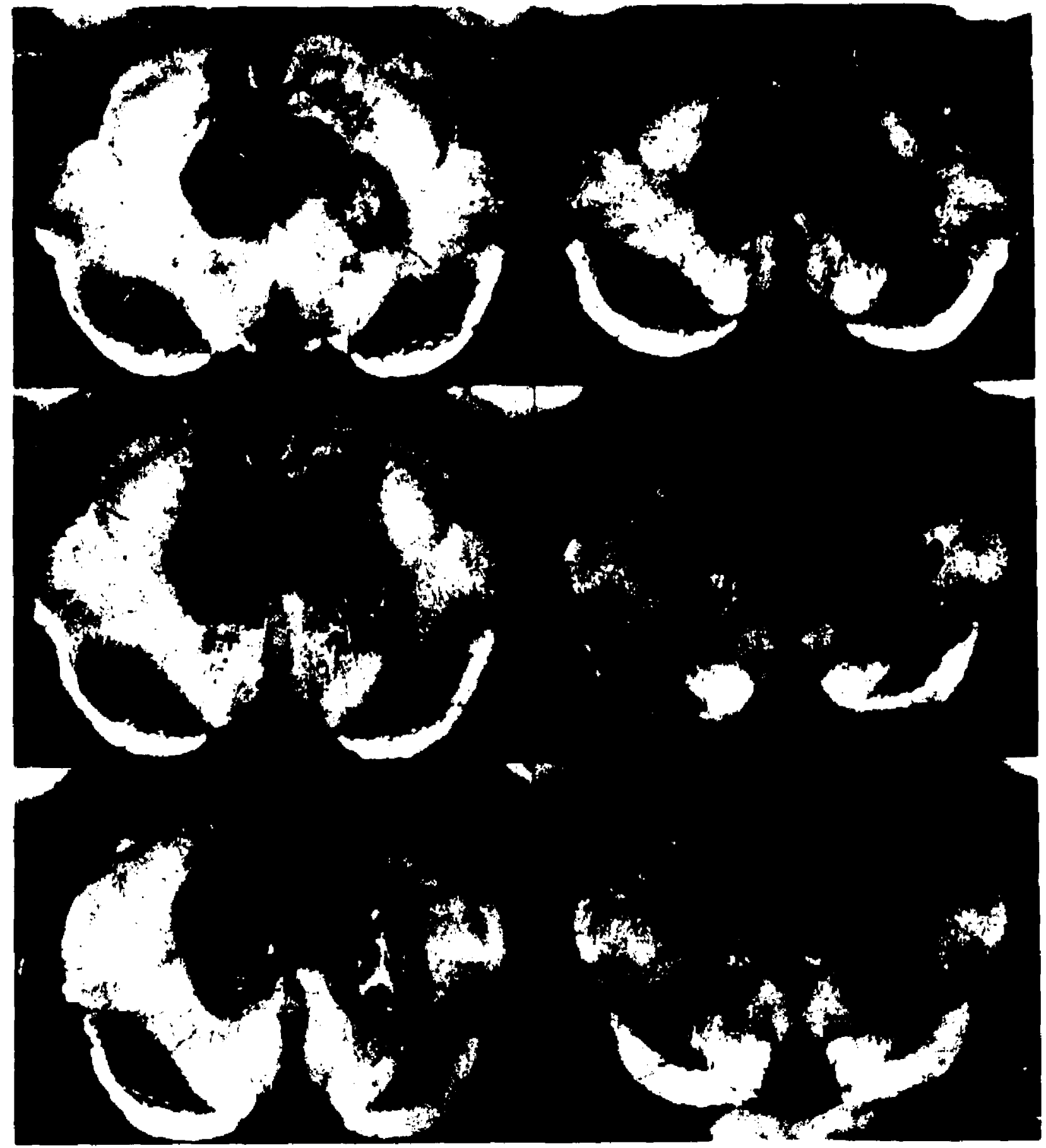

Figure 5. Unstained sections showing asymmetrical lesions in the midbrain. Left column: AML-25. Size Retention $=-27 \%$ savings; Threshold errors $=0,2,0,2$; Form Retention $=87 \%$. Right column: AML-19. Size Retention $=$ -275\%; Threshold errors $=0,2,4$, 15+; Form Retention = $-87 \%$. 


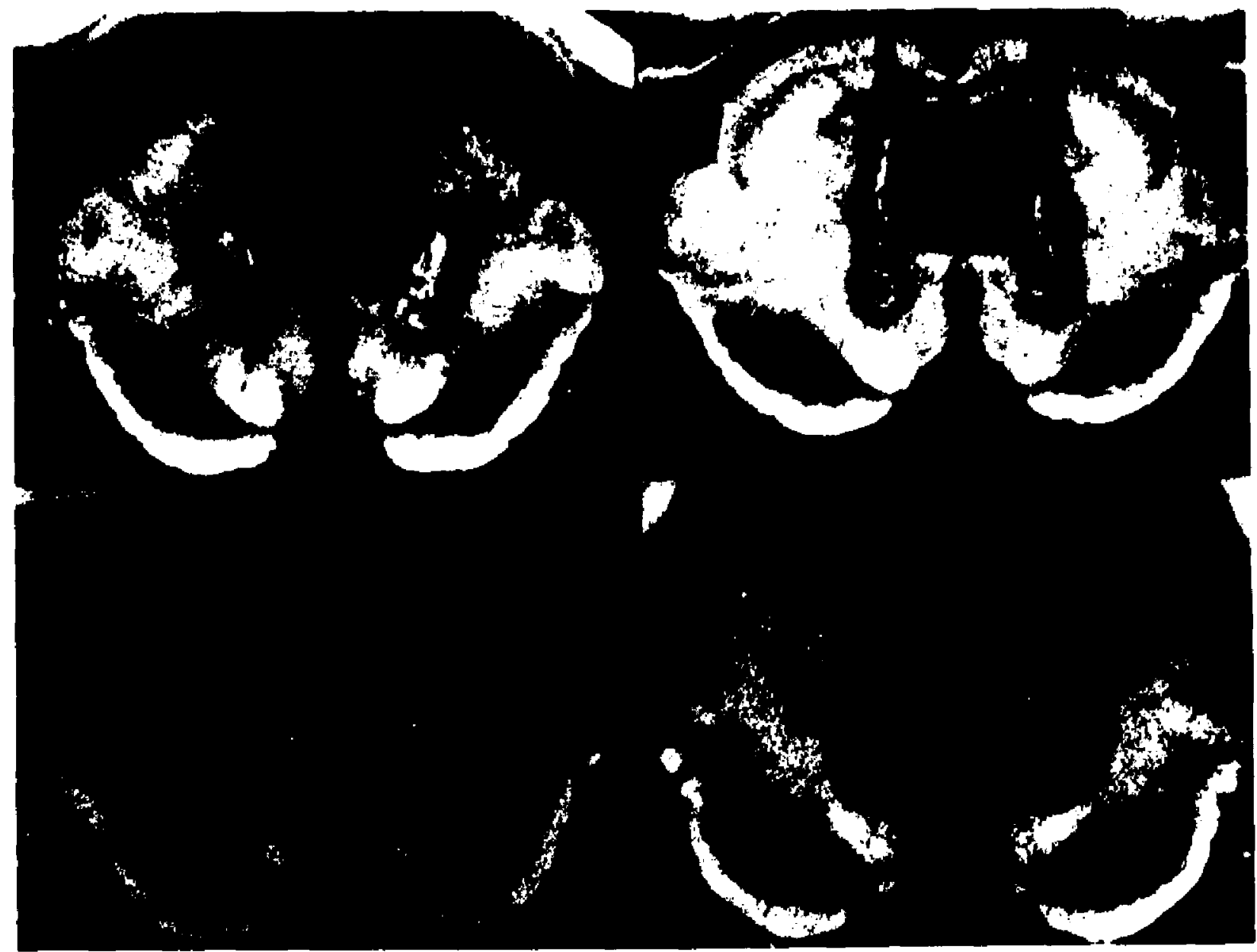

Figure 6. Unstained sections showing bilateral lesions in the region of the red nucleus. Upper left: RN-3. Size Retention $=-318 \%$ savings; Threshold errors $=0,0,7$, 15+; Form Retention $=25 \%$. Upper right: RN-4. Size Retention $=-145 \%$; Threshold errors $=0,0,0,15+$; Form Retention $=17 \%$. Lower left: RN-16. Size Retention $=-300 \%$; Threshold errors $=0,15+,-,-$; Form Retention $=-19 \%$. Lower right: RN-20. Size Retention $=-640 \%$; Threshold errors $=4,7,15+,-$; Form Retention $=36 \%$. 


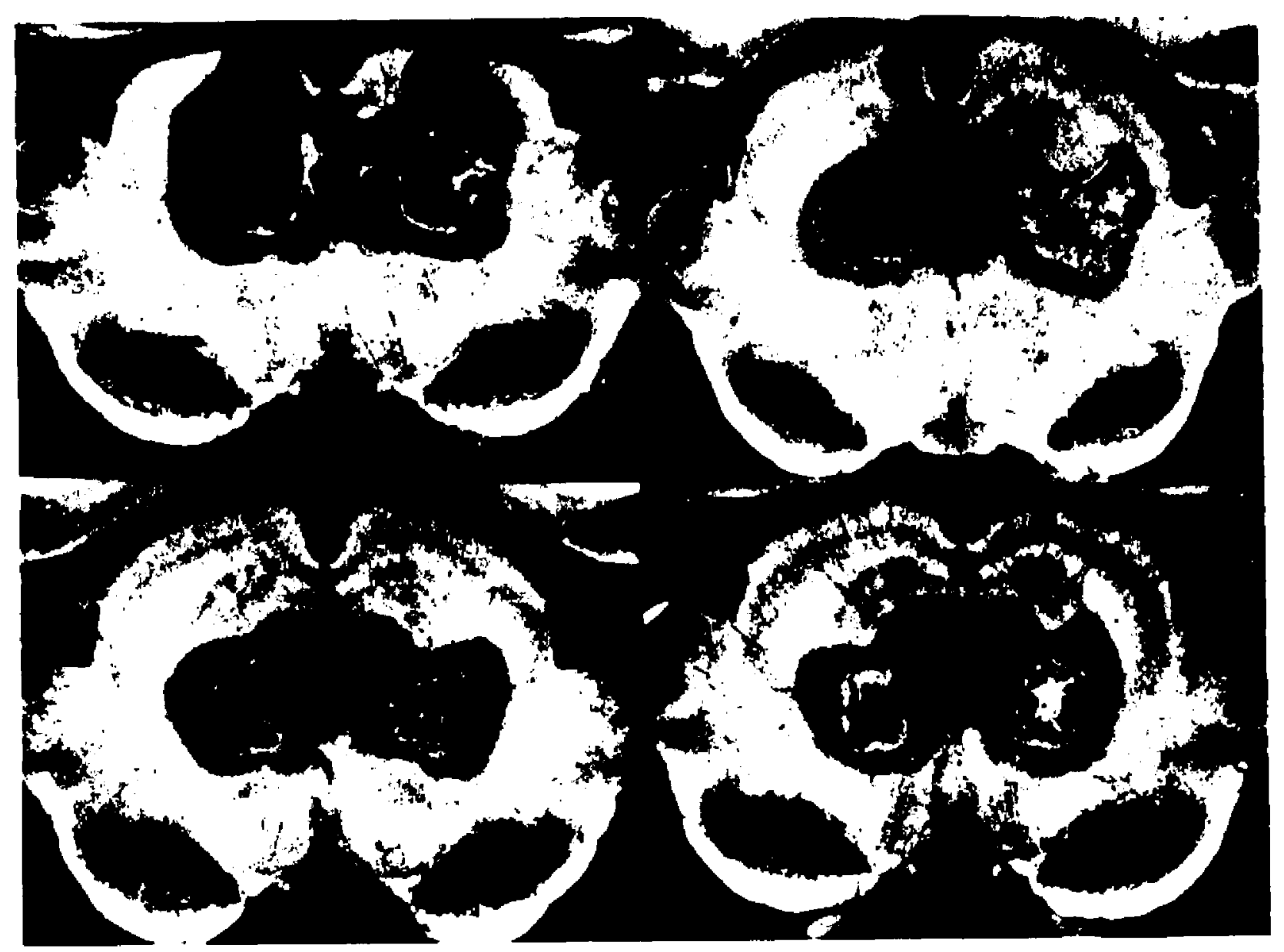

Figure 7. Unstained sections showing bilateral lesions dorsal to the red nucleus. Upper left: DRN-32. Size Retention $=89 \%$ savings; Threshold errors $=0,0,2,15+$; Form Retention $=100 \%$. Upper right: DRN-11. Size Retention $=18 \%$; Threshold errors $=2,0,0,0$; Form Retention = $100 \%$. Lower left; $\mathrm{DRN}-1$. Size Retention $=-144 \%$; Threshold errors $=3,4,14,15+$; Form Retention $=75 \%$. Lower right: DRN-33. Size Retention $=-45 \%$; Threshold errors $=$ 2, 2, 1, 7; Form Retention = 100\%. 


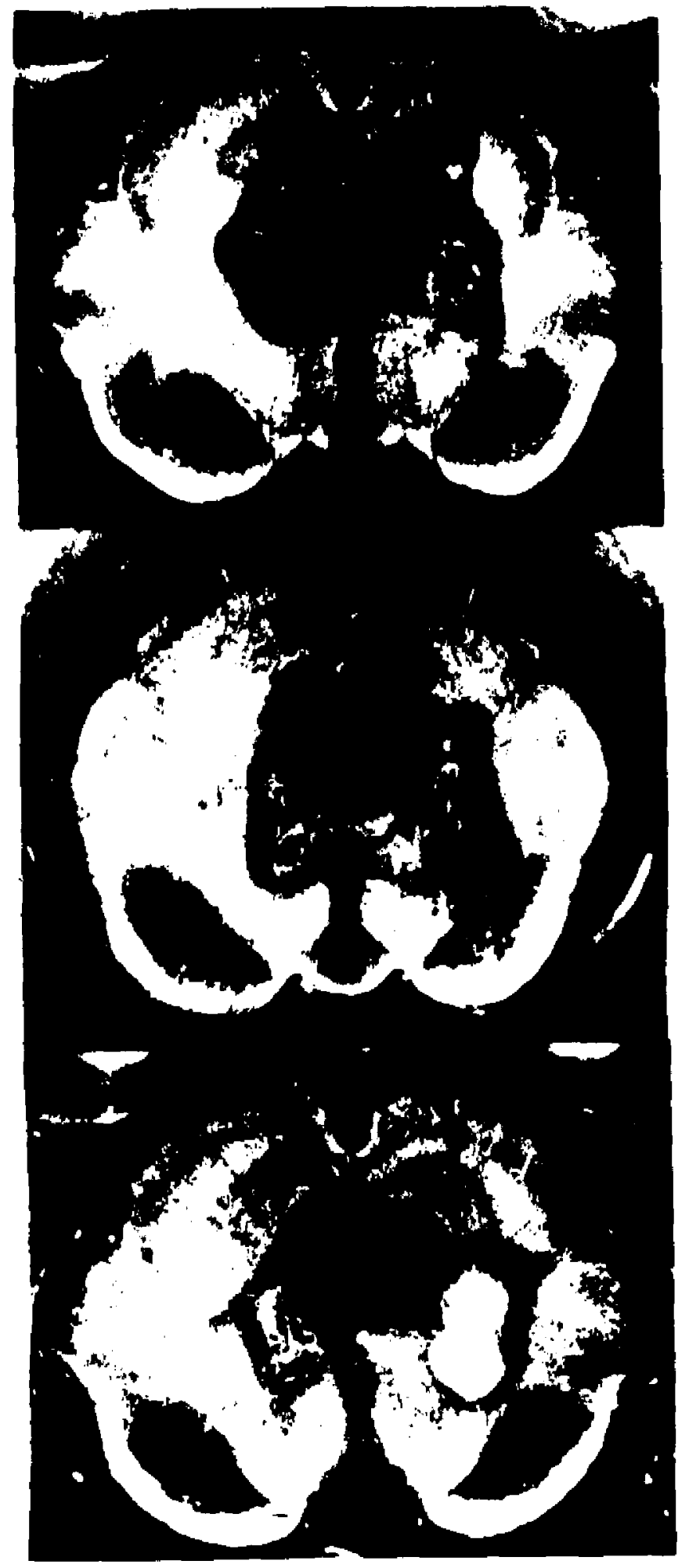

Figure 8. Unstained sections showing asymmetrical lesions in the midbrain. Top: AML-5. Size Retention = $-347 \%$; Threshold errors $=0,0,3,15+$; Form Retention = 62\%. Middle: AML-6. Size Retention $=-225 \%$; Threshold errors $=0,3,0,15+$; Form Retention $=53 \%$. Bottom: AML-13. Size Retention $=-183 \%$; Threshold errors $=0,0$, 2, 15+; Form Retention $=53 \%$. 


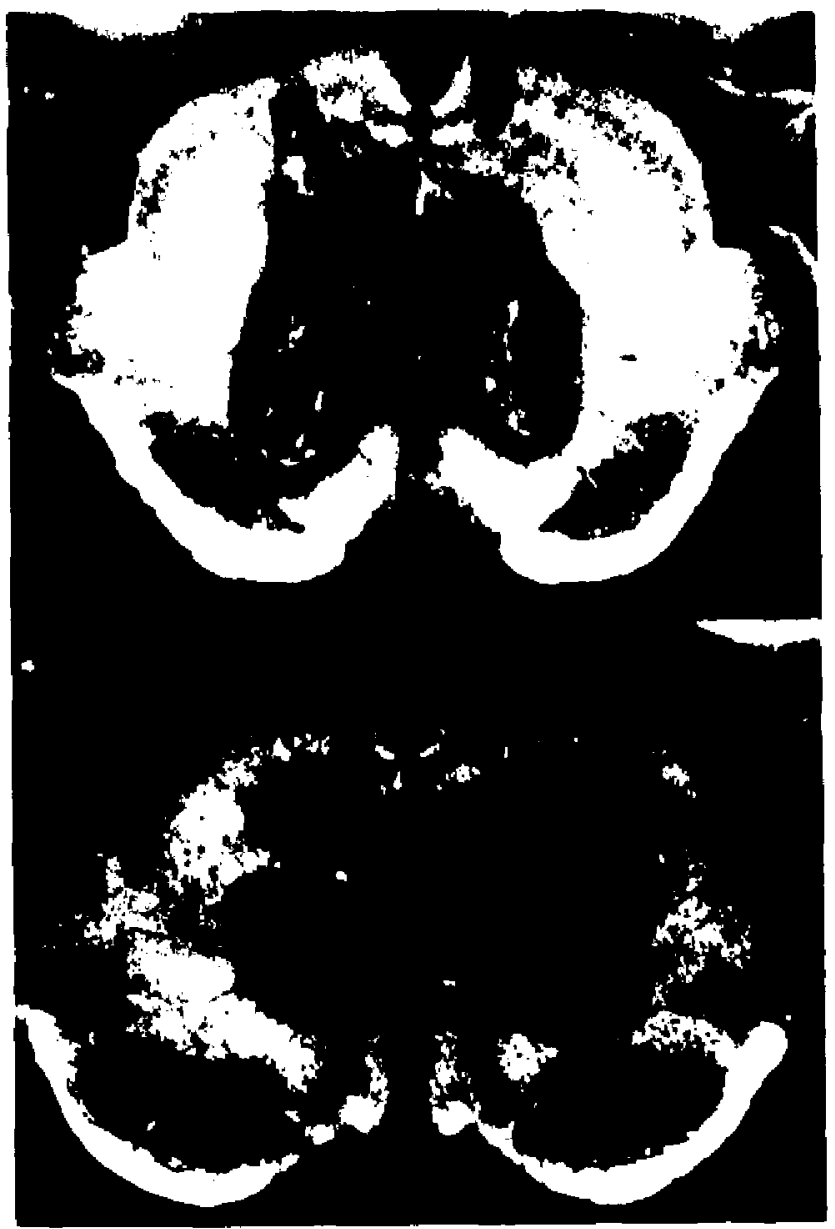

Figure 9. Unstained sections showing asymmetrical lesions of the midbrain. Top: AML-22. Size Retention = -138\%; Threshold errors $=0,0,0,12$; Form Retention $=$ 82\%. Bottom: AML-23. Size Retention $=-100 \%$; Threshold errors $=0,12,15+,-$; Form Retention $=39 \%$. 
and/or (2) forcing $\underline{S}$ into a position so that his mouth area would remain in contact with the wet mash placed in a food dish (glass coaster). If these methods were insufficient to maintain $\underline{S}^{\prime} \mathrm{s}$ weight after approximately 7 days, $\underline{\mathbf{S}}$ was then placed for several hours a day into a container (small plastic wastebasket) with a wet mash solution from $1 / 2$ inch to $3 / 4$ inch deep. These methods were terminated when $\underline{s}$ began eating the food solution from the dish located in his home cage. Drinking from the water bottles was rarely observed in the operate $\underline{s} s$ throughout the entire recovery period. The disturbance in attitudinal adjustment was also common to $\underline{S} s$ in the three operate groups. Essentially, when S was held by the tail and lowered to the surface of the table, he tucked his head so as to contact the table with the back of his neck. Normal Ss would, on the other hand, raise their heads and stretch out their forelegs, thus coming in contact with the table surface with the fore paws. This disturbance was transitory in most $\underline{s}$, and was not severe in any $\underline{S}$ at the time of testing.

A pupillary disturkance was manifested by several $\underline{S}$ of each operate group during the first postoperative week. It consisted of abnormal dilation of one or both pupils. This disturbance persisted in only one $\underline{S}$ (AML-23).

Canting of the head and locomotor circling were prevalent especially in the Ss of group AML, and were not uncommon 
during the first 12 hours postoperatively in the $\underline{s}$ of groups RN and DRN. Locomotor circling disappeared within the first postoperative week and head canting was minimal or unobservable by the time of testing.

Obstinate progression, operationally defined in the present case as repeatedly locomoting off the edge of a table, was a transient phenomenon observed in all $\underline{\mathrm{S}} \mathrm{s}$, with the exception of $D R N-33$. This rat suffered brain damage immediately dorsal to the anterior portion of the red nucleus. In general, the disappearance of this disturbance coincided with the recovery of vibrissae movement and exploratory activity which was observed between 3 to 12 days after the operation.

The most severe disturbance in gait occurred in two rats ( $R N-2$ and $R N-24)$ which suffered extensive damage to the anterior region of the red nucleus. For the first few days following the operation, s's locomotor behavior consisted of crawling with his belly on the table. A lower gait than normal (running close to the table) was observed in other $\underline{s} s$ with ventral lesions. One $\underline{S}$ (DRN-11) manifested a higher than normal gait (prancing) the first 2 postoperative days. However, the gait of all Ss appeared normal with the recovery of exploratory activity.

Although all animals were judged to be tame, several Ss within each group seemed to be excitable and resisted 
handling. This was transient and disappeared within the first postoperative week.

The relative duration of the behavior disturbances in the different $\underline{S} s$ paralleled the duration of $\underline{S} s$ disturbance in eating.

It is of great importance that during retention testing following the 21 to 26 -day postoperative recovery period, the operate $\underline{s}$ were generally indistinguishable from the controls. They showed good orientation toward the stimulus cards, exhibited frequent VTE's, appeared motivated to enter the goal box, and essentially were no different from normals in their correction of errors or in their reaction to shock. 


\section{DISCUSSION}

The results of the present study clearly agree with previous reports (Thompson, 1963a; Thompson, et al., 1964; Thompson, et al., 1967) that lesions in the area of the red - nucleus seriously impair retention of visually guided behavior. The finding that lesions centerè in the region of the red nucleus lead to significantly greater deficits than those more dorsally placed is also in agreement with the earlier observations of Thompson (1963a) on rats and of Myers (1964) on cats.

Myers (1964) investigated the effects of ablations of areas dorsal to the red nucleus (superior colliculus, dorsal tegmentum, and central grey) on retention of pattern discriminations. He found that if lesions of the dorsal midbrain extended into the ventral central grey or into the ventral adjoining tegmentum, the result was a prolonged disturbance in relearning of the difficult visual discrimination. Furthermore, Myers found, within rather broad limits, a direct relationship between the degree of the retention deficit and the extent of tegmental involvement. The results of the present study, on the other hand, clearly show that the locus of the midbrain lesion, rather than the size or extent of tegmental involvement, is critical. 
That ss suffering lesions dorsal to the red nucleus exhibited a gignificant retention deficit on the size discrimination but not on the subsequent form discrimination, would seem to conflict with the findings of Thompson (1963a) and Myers (1964). However, considering the difficulty of the visual discrimination task, the present findings are not inconsistent with either study. Thompson (1963a) found that destruction of the periaqueductal grey matter and the dorsal lateral tegmentum had no effect on retention of a simple black-white discrimination. It should be noted that the first retention problem used in the present study was substantially more difficult than the brightness problem used by Thompson (1963a). The second problem (form discrimination), considering the transfer effects resulting from the previous experience of the $\underline{s} s$ on the size discrimination, becomes very closely equated in difficulty with the simple brightness problem. [Compare mean errors to learn the form discrimination in the present study with mean errors to learn the simple brightness discrimination in previous reports of Thompson (1963a), Thompson and Rich (1961), and McNew, B. and Thompson (1966).] Hence, the results of the present study are consistent with the previous observations of Thompson (1963a) in that lesions dorsal to the red nucleus have little or no effect on retention of rather simple visual discriminations. 
Myers (1964) found that midbrain leaions dorsal to the red nucleus may disturb retention performance on difficult discriminations. This is consistent with the present findings to the extent that dorsal lesions produced a retention deficit on the difficult size discrimination. Thus, the present study, along with the previous reports of Thompson (1963a) and Myers (1964) suggest that midbrain lesions dorsal to the red nucleus disturb retention performance of difficult, but not simple visual discriminations.

Observations of the $\underline{S} s$ in the apparatus during postoperative training confirm the conclusions arrived at earlier in this paper that neither peripheral-motor, attentional, nor motivational disturbances can account for the retention deficits observed following ventral midbrain lesions. Although a sensory-perceptual deficit may indeed contribute to the poor retention performance, the results of the present study suggest that a disturbance in integrative-memory functioning rather than a sensory-perceptual loss is primarily responsible.

Evidence implicating involvement of a disturbance in sensory-perceptual processes is two-fold: (1) $\underline{\text { ss sustaining }}$ damage to the region of the red nucleus, as a group, performed significantly poorer than normal controls on the visual size threshold discrimination, and (2) difficulty manifested by all operate $\underline{S} s$ on the size threshold task was 
significantly correlated with subsequent retention impairment on the form discrimination task.

That a sensory-perceptual 10ss to not primartly responsible for the retention deficit is suggested by several other findings. First, difficulty on the size threshold was not significantly correlated with retention loss on the original size discrimination. Secondly, the three operate groups-- $\underline{S} s$ sustaining brain damage to the red nucleus, $\underline{s}$ receiving lesions dorsal to the red nucleus, and $\underline{S} s$ suffering asymmetrical midbrain lesions--did not differ significantly in regards to sensory-perceptual impairment as reflected by their performance on the threshold tasks. But, the groups did significantly differ from each other in retention performance on both the size discrimination and the form discrimination. It is unlikely that a disturbance in sensory-perceptual processes can account for the differential retention impairment found among the three operate groups. Finally, no significant correlation was found between threshold and retention performance for those Ss receiving rubral lesions.

The results of this investigation lend credence to a centrencephalic view of brain functioning (Penfield, 1954) and support the conception put forth by Thompson (1965) that the HMA (ventral mesencephalon along with the posterior lateral hypothalamus) serves as the core of the centrencephalic brain system. Subjects suffering brain damage to the 
region of the red nucleus manifested a disturbance in retention on both the visual size discrimination and the visual form discrimination, where the latter problem was presented to the animals after they had extensive experience on the more difficult visual size discrimination problems. The disruption of these habits by rubral damage, as mentioned earlier, cannot be readily accounted for by peripheral-motor, attentional, motivational, or sensory-perceptual disturbances. The data leaves little doubt of the great significance of this area in the mediation of learned behavior. However, the precise role or function of this ventral midbrain region remains speculative.

The centrencephalic model of Thompson (1965) suggests that the function of the HMA which includes the region of the red nucleus is the core of a system concerned with the integration and storage of extrinsic (sensory) and intrinsic (motivational) information, and is also concerned with the utilization of this information in directing the animal towards a goal. It is in this general area of the red nucleus that memory traces or engrams are hypothesized to be formed and later excited and compared with present experience in the initiation of visually guided behavior. According to this view, a lesion in the area of the red nucleus would destroy the substrate subserving an integrative-memory function. 
An alternate view is that damage to the region of the red nucleus only indirectly dierupte normal memory functions by altering the physlology of forebrain structures (Myers, 1964) or altering the essential level of cortical tonus (Lashley, 1954). Indeed, large tegmental lesions may cause changes in EEG patterns recorded over the entire cerebrum (Lindsley, Schreiner, Knowles, \& Magoun, 1950). However, even with large lesions, which was not the case in the rubral damaged $\mathbf{S} s$ of the present experiment, a disturbance in cortical tonus, as reflected by EEG patterns, is reversible with an extensive recovery period (Doty, Beck, \& Kooi, 1959). Although there is no doubt that the functional integrity of the visual cortex of the rat is of great importance in the mediation of complex visual discriminations, it remains to be seen how disruption in the integrity of the visual cortex by rubral damage could possibly cause the devastating effects on retention of visually guided behavior found in this investigation. The present author, in line with the centrencephalic view of brain functioning, would rather assign to the visual cortex the sensory-perceptual functions of analyzing and synthesizing visual information rather than attributing to it an integrative-memory function. 


\section{SUMMARY}

Previous research has indicated that the region of the red nucleus plays an important role in retention of visual habits. In addition, these earlier investigations strongly suggest that the retention loss produced by rubral lesions cannot be accounted for by either a peripheral motor disturbance, an attentional deficit, or an impairment in motivational-emotional functioning.

The purpose of the present study was to ascertain whether the abolishment of visual discrimination habits by damage to the area of the red nucleus results primarily from a sensory-perceptual $10 s 8$ or an integrative-memory deficit.

Four groups of rats--group RN, Ss receiving bilateral red nucleus lesions; group DRN, $\mathbf{s} s$ suffering brain damage dorsal to the red nucleus; group AML, Ss sustaining asymmetrical midbrain damage; and group NC, normal controls-were first tested for retention of a preoperatively learned visual size discrimination, then tested on size discrimination threshold, and subsequently tested for retention of a preoperatively learned form discrimination habit.

The group RN manifested a significantly greater deficit on the retention tasks than groups DRN, AML, and NC. Groups RN, DRN, and AML did not differ in their size threshold performance, although they all performed significantly 
poorer than group NC.

In line with a centrencephalic model of brain functioning, a disturbance in integrative-memory processes was interpreted to be primarily responsible for retention impairment produced by rubral damage. 


\section{REFERENCES}

Abrahams, V. C., Hilton, S. M. \& Zbrozyna, A. Active muscle vasodilatation produced by stimulation of the brain stem: Its significance in the defense reaction. Journal of Physiology, 1960, 154, 491-513.

Allen, W. F. Formatio reticularis and reticulo-spinal tracts, their visceral functions and possible relationships to tonicity and clonic contractions. I. Wash. acad. Sc., 1932, 22, 490 .

Bard, P. A diencephalic mechanism for the expression of rage with special reference to the sympathetic nervous system. Am. I. Physiol., 1928, 84, 490-515.

Breen, T. \& Thompson, R. Cortical and subcortical structures mediating a visual conditioned response motivated by thirst. I. comp. physiol. Psychol., $1966,61,146-150$.

Brodal, A. Neurological anatomy in relation to clinical medicine. Oxford: Oxford Univ. Press, 1948 .

Carpenter, M. B. A study of the red nucleus in the rhesus monkey. I. Comp. Neurol., 1956, 105, 195-239.

Carpenter, M. B. \& McMasters, R. E. Lesions of the substantia nigra in the rhesus monkey: Efferent fiber degeneration and behavioral observations. Am. Anat., 1964, 114, 239-320.

Crosby, E. C. \& Woodburn, R. T. The mammalian midbrain and isthmus regions: Part II, The fiber connections: $C$. The hypothalamo-tegmental pathways. ‥ comp. Neurol., $1951, \underline{94}, 1-32$.

Delgado, M. M. R. Sequential behavior induced repeatedly by stimulation of the red nucleus in free monkeys. Science, 1965, 148, 1361-1363.

Doty, R. W., Beck, E. C., \& Kooi, K. ... Effect of brain stem lesions on conditioned responses in cats. Expt. Neurol., 1959, 1 , 360-385. 
French, J. D. The reticular formation. In Field, J., Magoun, H. W., \& Hall, V.E. (Eds.) Handbook of Physiology. Vol. 2. Washington, D.C.: American Physiology Society, 1960.

Fuster, J. M. Effects of atimulation of brain stem on tachistoscopic perception. Science, 1958, 127, 150.

Gerebtshoff, M. A. \& Wauters, A. Recherches sur l'ecorce cerebrale et le thalamus du cobaye. II. Systematisation cortico-thalamique et voies efferentes de l'ecorce cerebrale. La cellule, 1941-1943, Tome 4a, $5-70$.

Hinsey, J. C., Ranson, S. W., \& McNatin, R. G. The role of the hypothalamus and mesencephalon in locomotion. Archives of Neurol. \& Psychiat., 1930, 23, 1-43.

Jung, R. \& Hassler, R. The extrapyramidal motor system. In Field, J., Magoun, H. W., \& Hall, V. E. (Eds.) Handbook of physiology. Vol. 2. Washington, D.C.: American Physiological Society, 1960.

Keller, A. D. Autonomic discharges elicited by physiological stimuli in midbrain preparations. Am. J. Physiol., $1932,100,576-586$.

Knook, H. L. The fibre connections of the forebrain. Philadelphia: F. A. Davis, Co., 1966.

Krieg, W. J. S. The hypothalamus of the albino rat. J. comp. Neurol., 1932, 55, 19-89.

Kruskal, W. H. \& Wallis, W. A. Use of ranks in one-criterion variance analysis. I. Amer. Statist. Assoc., 1952, 47, 583-621.

Lashley, K. S. Brain mechanisms and intelligence. Chicago: Univ. Chicago Press, 1929.

Lashley, K. S. Dynamic processes in perception. In Delafresnaye, J. F. (Ed.) Brain mechanisms and consciousness. Springfield, I11.: Thomas, 1954 .

Lindsley, D., Schreiner, L. H., Knowles, W. B., \& Magoun, H. W. Behavioral and EEG changes following chronic brain stem lesions in the cat. Electroencephalography clin. Neurophysiol., 1950, 2, 483-498. 
Magoun, H. W. The waking brain. Springfield, Ill.: Charles C. Thomas, 1958 .

Mann, H. B. \& Whitney, D. R. On a test of whether one of two random variables is stochastically larger than the other. Ann. Math. Statist., 1947, 18, 50-60.

Massopust, L. C. A stereotaxic atlas of the diencephalon of the rat. In Sheer, D. E. (Ed.) Electrical stimulation of the brain. Austin, Texas: Univ. Texas Press, 1961. Pp. 182-202.

McNew, B. R. The effect of pretectal lesions on retention of a brightness discrimination habit in the rat. Unpublished Master's thesis, Louisiana State University, 1965 .

McNew, B. R. \& Thompson, R. The effect of posterior thalamic lesions on retention of a brightness discrimination habit motivated by thirst. I. comp. physiol. Psychol., $1966,62,125-128$.

Myers, R. E. Visual deficits after lesions of brain stem tegmentum in the cat. Archives of Neurol., 1964, 11 , 73-90.

Nauta, W. J. H. Hippocampal projections and related neural pathways to the midbrain in the cat. Brain, 1958, 81, 319-340.

Penfield, w. Studies of the cerebral cortex of man: A review and an interpretation. In Delafresnaye, J. F.

(Ed.) Brain mechanisms and consciousness. Springfield, I11.: Charles C. Thomas, 1954. Pp. 284-304.

Rich, I. \& Thompson, R. Role of the hippocampo-septal system, thalamus, and hypothalamus in avoidance conditioning. I. comp. physiol. Psychol., 1965, 59, $66-72$.

Rinvik, E. The cortico-rubral projection in the cat: Further observations. Expt1. Neurol., 1965, 12, 278291.

Siegel, S. Nonparametric statistics. New York: McGrawHill Book Co., 1956 . 
Sprague, J. M., Levitt, M., Robson, K., Liu, C. N., Stellar, E., \& Chambers, W. W. A neuroanatomical and behavioral analysis of syndromes resulting from midbrain lemniscal and reticular lesions in the cat. Arch. Ital. Biol., 1963, 101, 225-295.

Teuber, H. I. Perception. In Fleld, J., Magoun, H. W., \& Hall, V. E. (Eds.) Handbook of Physiology. Vol. 3. Washington, D. C.: American Physiological Society, 1960.

Thompson, R. Retention of a brightness discrimination following neocortical damage in the rat. I. comp. physiol. Psychol., 1960, 53, 212-215.

Thompson, R. Cortical and subcortical structures mediating visual discrimination habits in the rat. Bol. Inst. Estud. Med. Biol., Mex., 1963, 21, 451-466. (a)

Thompson, R. Thalamic structures critical for retention of an avoidance conditioned response in rats. I. comp. physiol. Psychol., 1963, 56, 261-267.

Thompson, R. Centrencephalic theory and interhemispheric transfer of visual habits. Psychol. Rev., 1965, $\underline{72}$, 385-397.

Thompson, R. \& Hawkins, W. F. Memory unaffected by mamillary body lesions in the rat. Exptl. Neurol., 1961, 3, 189-196.

Thompson, R., Lukaszewska, I., Schweigerdt, A., \& McNew, $\mathrm{J}$. J. Retention of visual and kinesthetic discriminations in rats following pretecto-diencephalic and ventral mesencephalic damage. I. comp. physiol. Psychol., 1967, in press.

Thompson, R., Malin, C. F., \& Hawkins, W. F. Effect of subcortical lesions on retention of a kinesthetic discrimination habit. Exptl. Neurol., 1961, $\underline{3}, 376-374$.

Thompson, R. \& Massopust, L. C. The effect of subcortical lesions on retention of a brightness discrimination in rats. I. comp. physiol. Psychol., 1960, 53, 488496 .

Thompson, R. \& Rich, I. A discrete diencephalic pretectal area critical for retention of visual habits in the rat. Exptl. Neurol., 1961, 4, 436-443. 
Thompson, R., Rich, I., \& Langer, S. K. Lesion studies on the functional signiflcance of the posterior thalamomesencephalic tract. I. comp. Neurol., 1964, 123, 29-44.

Waller, W. H. Progression movements elicited by subthalamic stimulation. I. Neurophysiol., 1940, 3 , 300-307.

Wood, J. W. Behavior of chronic decerebrate rats. I. Neurophysiol., 1964, 27, 635-644. 


\section{VITA}

James Johnston McNew was born October 22, 1936 in Mount Vernon, Ohio. He attended Ohio Wesleyan University and received a Bachelor of Arts degree in 1958. He entered graduate school at Louisiana state University in the fall of 1958. After two years of Graduate School, he was drafted into the U. S. Army. He then returned to Louisiana state University as a full-time graduate student in the fall of 1963 and received a Master of Arts degree in 1965. 
EXAMINATION AND THESIS REPORT

Candidate: James Johnston McNew

Major Field: $\quad$ Psychology

Title of Thesis: The Role of the Red Nucleus in Visually Guided Behavior in the Rat.

Approved:
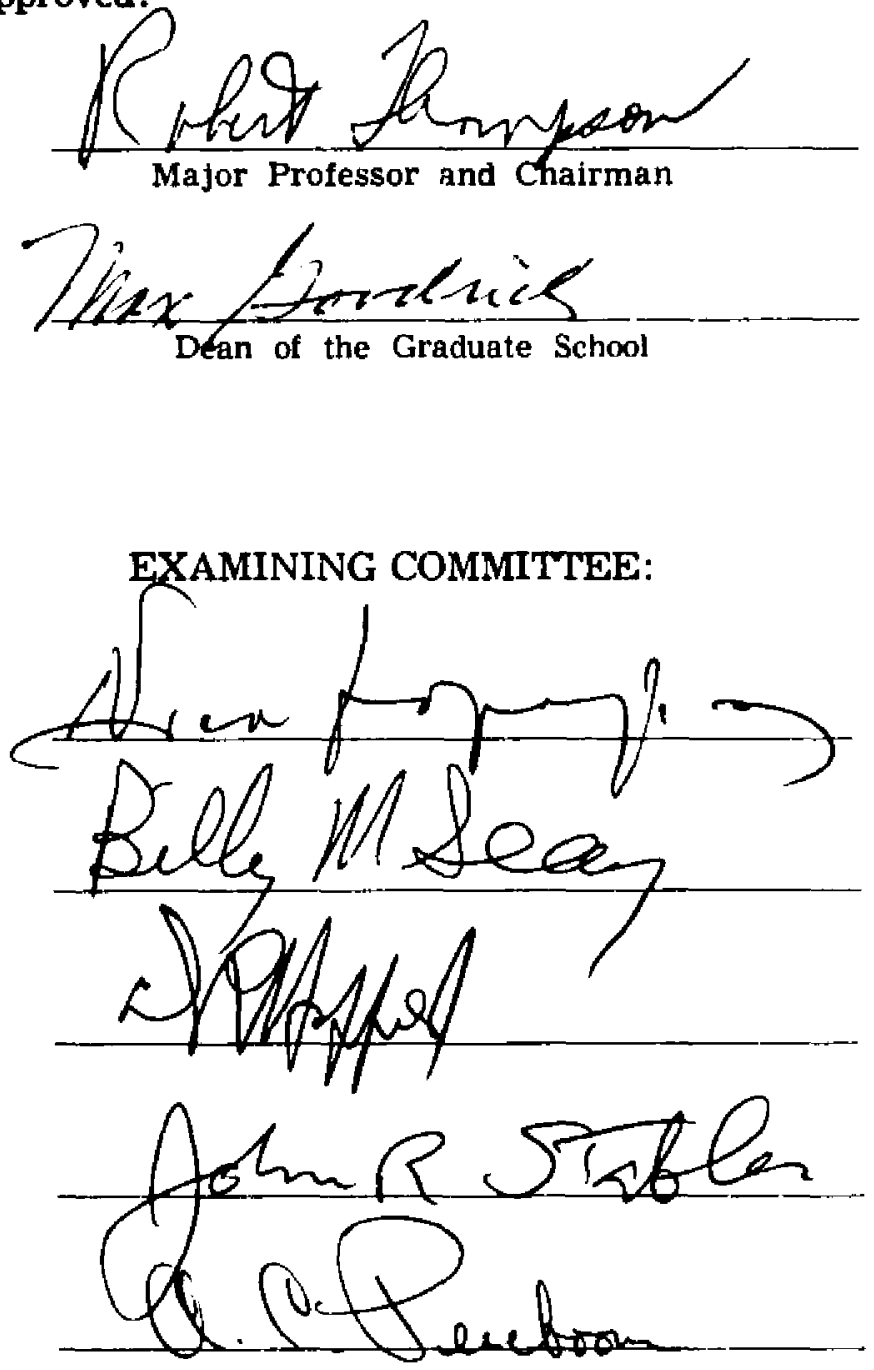

Date of Examination:

January 26,1967 